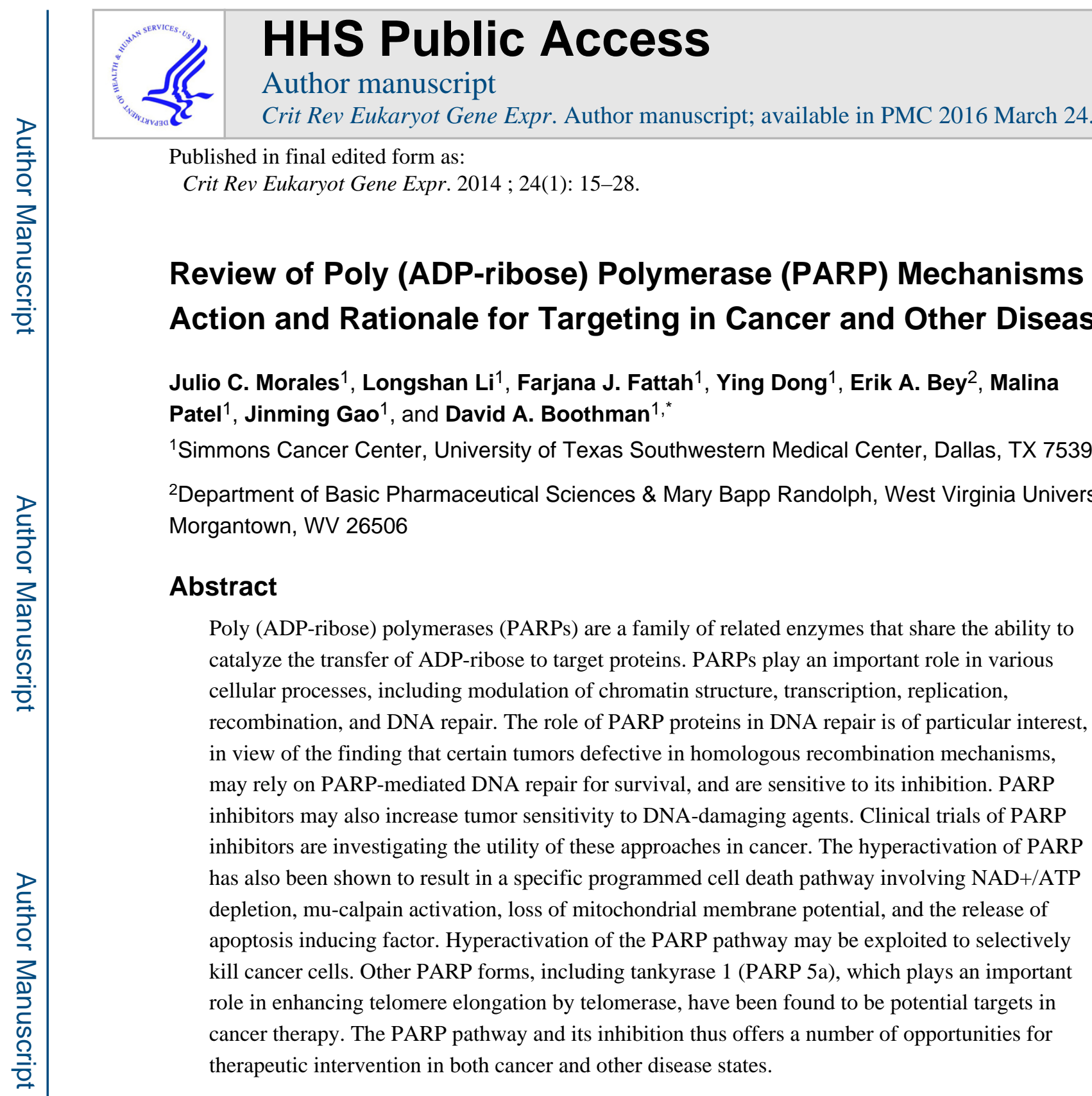

\title{
Keywords
}

Parp1; DNA repair; metabolism; $\beta$-lap; DNA damage; hyperactivation; synthetic lethality; chromatin; programmed necrosis

\section{WHAT IS PARP?}

The poly (ADP-ribose) polymerases (PARPs) are an emerging family of enzymes that share the ability to catalyze the transfer of ADP-ribose to target proteins (poly ADPribosylation). ${ }^{1,2}$ There are at least 18 members of the PARP family that are encoded by different genes, and share homology in a conserved catalytic domain. ${ }^{1}$ Although some isoforms including PARP1 and PARP2 are best known for their involvement in DNA repair

*Address all correspondence to: David A. Boothman, University of Texas Southwestern, 6001 Forest Park Dr. North Campus ND2.210, Dallas, TX 75390; Tel.: 214-645-6371; Fax: 214-645-6347; david.boothman@utsouthwestern.edu. 
processes, it is now clear that these and other PARPs have an important role in several cellular processes including cell proliferation and cell death. ${ }^{1}$ A number of cellular substrates for PARP have been defined, and a majority of these proteins are nuclear proteins that are involved in nucleic acid metabolism, modulation of chromatin structure, DNA synthesis, and DNA repair. ${ }^{2}$ PARP also automodifies itself in the presence of DNA strand breaks, and is one of the main acceptors of poly ADP ribose in vivo. ${ }^{2}$ PARP1 is the first and best characterized member of the PARP family. PARP2 is most closely related to PARP1 with $69 \%$ similarity in its catalytic domain, and was identified on the basis of the persistence of PARP activity in PARP1-deficient cells. ${ }^{1,3}$

\section{ROLE OF PARP IN DNA REPAIR}

Evidence for an important role of PARP in DNA repair comes from the finding that DNA damaging agents and radiation-induced DNA damage causes increased PARP activity. ${ }^{4}$ The accumulation of DNA lesions has also been found to result in a significant increase in PARP levels in cells. ${ }^{5}$ PARP is involved in base excision repair (BER) in response to singlestranded DNA breaks (SSBs) and is a component of the BER complex, which consists of DNA ligase III, DNA polymerase beta, and the XRCC1 protein. ${ }^{6}$ In cell-free systems, it has been shown that the unmodified PARP enzyme binds tightly to DNA strand breaks and following auto-poly ADP-ribosylation, is released and allows for repair enzyme access to the damaged DNA. ${ }^{2,7}$ Both PARP1 and PARP2 also interact, and share common partners in the SSB repair and BER pathways, although PARP2 also has unique partners, such as the telomeric protein TRF-2. ${ }^{1,8,9}$

It has been shown that PARP1 plays a role in nucleotide excision repair (NER), since NER processes are reduced with PARP1 inhibition. ${ }^{10}$ Both BER and NER are key pathways that enable repair of DNA damage that can be caused by certain alkylating and chemotherapeutic agents. ${ }^{11} \mathrm{PARP}^{-/-}$mice are therefore sensitive to alkylating agents such as N-methyl-Nnitrosourea (MNU) and gamma radiation exposure. ${ }^{12}$ An increased capacity for DNA repair and/or DNA repair activity is frequently found in cells that acquire resistance to chemotherapy agents such as platinum. ${ }^{13,14}$ In vitro studies demonstrate that cells resistant to cisplatin display an increased ability to repair cisplatin-DNA damage. ${ }^{13}$ Upregulation of DNA repair mechanisms is therefore one of several mechanisms by which tumor cells can become resistant to chemotherapies.

\section{INHIBITION OF PARP IN CHEMOTHERAPY}

Because of its role in DNA repair, PARP inhibition results in genomic instability and accumulation of damaged cells in cell cycle arrest. ${ }^{15}$ This shows that ADP ribosylation reactions are needed following DNA damage and for cells to progress through G2 and M phases of the cell cycle. ${ }^{15}$ The inhibition of PARP activity using dominant negative mutant PARPs has also been shown to result in an increase in apoptosis, which arises in part due to a reduced DNA repair capacity. ${ }^{16}$ It has been suggested that PARP is a key component of the cell cycle G2 checkpoint, which prevents a damaged cell with DNA strand breaks from being able to enter mitosis. ${ }^{16}$ Expression of a dominant negative DNA-binding domain of PARP thus sensitizes cells to SSB caused by alkylating agents. ${ }^{16,17}$ As noted earlier, 
$\mathrm{PARP}^{-/}$deficient mice are also extremely sensitive to gamma radiation, and DNA damaging agents cause rapid apoptosis in $\mathrm{PARP}^{-/-}$cells. ${ }^{12}$ These findings demonstrate the importance of PARP in post-DNA-damage repair. ${ }^{12}$ The viability of $\mathrm{PARP}^{-/}$mice further suggests that PARP is relatively dispensable for normal activity, but is an essential survival factor for DNA damage. ${ }^{12}$ These characteristics of PARP make it an attractive candidate for therapeutic inhibition in combination with cancer chemotherapy or radiotherapy.

There is evidence of upregulation of PARP activity in some cancer types. It has been shown that tumor tissue from hepatocellular carcinoma patients displayed significantly increased levels of ADP ribosylated PARP than did non-tumorous adjacent tissues. ${ }^{18}$ Recent results further indicate that PARP1 mRNA was upregulated in several tumor types with the most striking differences observed in primary tumors of the breast, endometrium, lung, ovary, and skin. ${ }^{19}$ In particular, a high expression of PARP1, but not PARP2, was found in triplenegative breast cancer (TNBC) tumors. ${ }^{19}$ The latter findings suggest that inhibition of PARP, either alone or in combination with DNA-damaging agents, could be a potential therapeutic approach in TNBC and other tumor types. ${ }^{19}$ This therapeutic approach is currently under investigation in several clinical development programs. Inhibition of PARP has potential for use in cancer treatment through at least two mechanisms, i.e., by increasing tumor sensitivity to chemotherapeutic agents that damage DNA, and also by inducing "synthetic lethality" in cells that are highly dependent on PARP, due to deficiency in HR, such as BRCA1 mutants (Fig. 1).

\section{INHIBITING PARP AND SYNTHETIC LETHALITY}

The breast cancer-associated gene BRCA1 is known to play an important role in repair of DS DNA breaks via homologous recombination (HR) because cells that are deficient in BRCA1 display impaired HR and an inability to repair defective chromosomes. ${ }^{20}$ Similarly, BRCA2 interacts with the DNA repair protein RAD51 and has also been shown to play an important role in HR because cells deficient in RAD51-interacting regions of BRCA2 display hypersensitivity to DNA cross-links and chromosomal instability. ${ }^{21}$ It has been shown that defects in HR repair mechanisms, arising from deficiencies in key repair proteins such as RAD51, DSS1, RPA1, or CHK1, cause cells to be highly dependent on the activity of PARP and therefore highly sensitive to its inhibition. ${ }^{22}$ It has been postulated that PARP inhibition compromises SSB repair and BER, and, in cells lacking intact HR mechanisms (e.g., BRCA1 and BRCA2 mutants), these are then converted into double-stranded breaks, resulting in cell lethality. ${ }^{23}$ Accordingly, it has been shown that cells deficient in BRCA1 or BRCA2 are, respectively, 57- and 133-fold more sensitive than normal cells to PARP inhibition. ${ }^{24}$ Thus, cells with defects in HR mechanisms may also be targeted with PARP inhibitors to further impair DNA repair mechanisms, resulting in "synthetic lethality." The benefit of this approach is that PARP inhibition is likely to be highly selective for tumors, for example, that are BRCA2 ${ }^{-/-}$in patients with BRCA2 heterozygosity. ${ }^{23,25}$ Immunoreactivity for PARP1, for example, was found in over $80 \%$ of BRCA1 tumors, suggesting that PARP inhibition may be a useful intervention for patients with breast cancer harboring BRCA1 mutations. ${ }^{26}$ Interestingly, however, it has been found that loss of 53BP1, a DNA-damage response factor, in BRCA1 tumors alleviated their recombination defect and reverted their hypersensitivity to DNA damage. ${ }^{27,28}$ Further, loss of 53BP1 appears to be 
common among both TNBC and tumors with BRCA1/2 mutations, suggesting that this may be an important biomarker for determining sensitivity to PARP inhibitors and/or DNA damaging agents in these tumors, or whether other therapeutic strategies might be necessary. ${ }^{27,28}$ An assay utilizing RAD51 focus formation has been developed to rapidly assess the HR state of tumors and their corresponding sensitivity to PARP inhibitors. ${ }^{29}$

\section{PARP FUNCTION IN CHROMATIN REMODELING}

Because chromatin structure can affect several important processes such as DNA transcription, replication, and repair, its modulation by PARP is important. ${ }^{2}$ Early studies demonstrated that poly ADP-ribosylation of DNA poly nucleosomes by PARP results in an overall relaxation of chromatin structure ${ }^{30}$ This relaxation of chromatin structure could be an important event that facilitates processes such as DNA replication, repair, and transcription of DNA. ${ }^{30}$ Relaxation of chromatin is also likely to allow damaged DNA to become more accessible to repair enzymes. ${ }^{30}$ More recent findings have shown that PARP1 functions as a recruiter and activator of proteins such as Alc1 that are involved in the remodeling of chromatin. ${ }^{31}$ In this study, the PARP1-mediated poly ADP-ribosylation of Alc1 both directed its recruitment to chromatin as well as activated its ATPase and chromatin remodeling activity. ${ }^{31}$ PARP2 also appears to function as a chromatin modulator, and it has been suggested, based on gene targeting studies in mice, that PARP1 and PARP2 share complementary, but not fully overlapping functions; double-mutant PARP1 and PARP-2-deficient mice are not viable. ${ }^{1}$

\section{PARP EFFECTS ON TRANSCRIPTION FACTORS AND EPIGENETIC FACTORS}

Early studies also suggested that PARP plays an important role in the regulation of DNA transcription, since PARP activity was found to be more abundant on regions of the chromatin that were transcriptionally active (euchromatin) and less associated with transcriptionally inert regions. ${ }^{32}$ Similarly, it has been shown that PARP serves as a transcriptional cofactor and could stimulate both activator-dependent as well as basal transcriptional activity mediated by RNA polymerase II. ${ }^{33}$ A role for PARP in the regulation of a specific gene has also been demonstrated by virtue of its interaction with a transcription enhancer factor TEF1, at MCAT promoter elements in the promoter region of the cardiac troponin T (cTNT) gene. ${ }^{34}$ In this study, PARP could ADP ribosylate TEF1, and MCATdependent transcriptional activity could be blocked by inhibition of PARP enzymatic activity, suggesting that PARP has a role in the modulation of muscle-specific gene transcription. ${ }^{34}$ Studies have also shown that PARP interacts with the transcription factor AP-2 and enhances its transcriptional activity as a coactivator in cell lines. ${ }^{35}$ Conversely, PARP can bind to nuclear receptors and inhibit ligand-dependent transcriptional activity mediated by receptors such as the retinoid $\mathrm{x}$ receptor (RXR). ${ }^{36}$ Taken together, these results suggest that poly ADP-ribosylation can serve to either stimulate or repress transcriptional activity and modulation of PARP may therefore have therapeutic implications for many disease states. Another more recently identified example of PARP1 function in transcription is its impact on the promoter regions of genes known to be regulated by PARP1. ${ }^{37}$ In this study, PARP1 was shown to promote a permissive chromatin environment onto which RNA 
polymerase II transcriptional machinery could be efficiently loaded; depletion of PARP1 activity caused these processes to become inefficient. ${ }^{37}$

\section{PARP1 HYPERACTIVATION AND PROGRAMMED NECROSIS}

PARP1 hyperactivation has also been shown to result in a specific programmed cell death pathway that is characterized by depletion of NAD+/ATP, calcium imbalance, mu-calpain activation, loss of mitochondrial membrane potential, rapid mitochondrial dysfunction, and release of apoptosis-inducing factor (AIF) resulting in cell death (Fig. 2).

\section{VIII. "ENERGY CRISIS": NAD+/ATP DEPLETION/MITOCHONDRIAL ENERGY}

\section{FAILURE}

Early studies showed that PARP was the key molecule that resulted in NAD+ depletion following exposure to DNA damaging agents and gamma radiation. ${ }^{4}$ As originally proposed by Berger as the "suicide hypothesis," in cells with extensive DNA damage or damage that is not repaired, PARP remains activated, leading to continued NAD+ depletion and further ATP consumption in order to resynthesize NAD+. ${ }^{38}$ This process escalates the energy crisis in the cell resulting in programmed necrosis. ${ }^{39}$ It has been shown that depletion of NAD+ and mitochondrial permeability transition are important sequential steps involved in PARP1mediated cell death. ${ }^{40}$ Furthermore, the restoration of NAD+ leads to recovery of mitochondrial membrane potential, and blocks translocation of AIF from the mitochondria to the nucleus. ${ }^{40}$ PARP1 activation has also been shown to induce a rapid mitochondrial dysfunction, which was followed by a collapse in mitochondrial potential, and release of AIF and cytochrome c. ${ }^{41}$ More recently, this mitochondrial energy failure has been shown to be a direct consequence of PARP1 hyperactivation; Chiarugi and coworkers have found that the PARP product poly ADP-ribose becomes catabolized to AMP via the action of poly ADP-ribose glycohydrolase (PARG) and nucleoside diphosphate X (NUDIX) hydrolases. ${ }^{42}$ The accumulated AMP then serves to compete with ADP for binding to the adenine nucleotide transporter, abrogating energy production by the mitochondria and further contributing to the "energy crisis." 42

\section{PAR FORMATION AND AIF RELEASE}

Dawson and coworkers first connected PARP1 hyperactivation with AIF release from mitochondria, signaling a caspase-independent programmed cell death pathway. ${ }^{43}$ Their studies showed that PARP1 was required for AIF release from the mitochondria, and that AIF was required for a PARP1-mediated cell death program that was caspase independent. ${ }^{43}$ Consequently, it was shown that poly ADP-ribose polymer, or PAR, was a "death signal" that causes AIF release from mitochondria in response to PARP1 hyperactivation; e.g., cells with reduced AIF are resistant to PARP1 mediated death or PAR toxicity. ${ }^{14}$ AIF release from mitochondria thus plays a major role in cell death induced by PARP1 (which is also termed "parthenatos"), a process that is not dependent on calpain activation. ${ }^{44}$ The translocation of AIF from the mitochondria to the nucleus has been shown to be required for cell death induced by agents such as arsenic trioxide. ${ }^{45}$ This mechanism also involves production of ROS and PARP1 hyperactivation, and PARP1 inhibitors can attenuate this cell 
death mechanism. ${ }^{45}$ Collectively, the data indicate that PARP1 activation triggered by ROS causes AIF release from mitochondria resulting in a caspase-independent cell death pathway. ${ }^{45}$ The translocation of AIF from mitochondria to the nucleus causes chromatin condensation and DNA fragmentation, and AIF downregulation confers resistance to DNA alkylating agent-induced necrosis. ${ }^{46,47}$ These findings demonstrate the importance of AIF as a mediator of cell death in the PARP pathway.

\section{POTENTIAL THERAPEUTIC ROLE(S) OF PAR/PARG MANIPULATION}

PARP enzymes function to convert NAD+ into polymers of ADP-ribose, or PAR, which, as noted earlier, plays an essential role in PARP-mediated cell death, however, there is also evidence that PAR may act on mitochondria directly, independent of NAD+ depletion. ${ }^{47,48}$ PAR polymer has been shown to be directly cytotoxic to neurons, and manipulation of the PAR polymer signal may therefore be of value in disease states that involve cellular injury. ${ }^{49}$ PARG is needed for the hydrolysis of PAR, and also has an important function in regulating cell death following DNA injury. ${ }^{50}$ Analysis of PARG-deficient mice suggests that PARG plays an important role in the maintenance of PAR levels. ${ }^{51}$ Studies have shown that in undamaged cells, PARG depletion is not detrimental, and could protect cells from spontaneous SSB and telomeric abnormalities. ${ }^{50}$ In contrast, PARG deficiency has been shown to increase the sensitivity of cells to radiation, by virtue of a defect in repair of SSB and DSB repair, leading to centrosome amplification and mitotic spindle defects; PARG could thus be another potential therapeutic target for radiotherapy, and PARG inhibition could be useful strategy to sensitize cells to DNA-damaging agents and chemotherapies. ${ }^{52-54}$ Inhibition of PARG may also be useful in physiologic conditions such as ischemia, inflammation, and stroke. ${ }^{53}$

Tight junctions are important in structures such as the blood-brain barrier (BBB), and the tight junction protein occludin has been found downregulated following PARP1 hyperactivation in animal models of ischemia-reperfusion injury, with an accompanying increase in BBB permeability. ${ }^{55}$ The PARP inhibitor PJ34 prevented the loss of occludin and preserved BBB function in this model, suggesting a therapeutic benefit of PARP inhibition in this disease state. ${ }^{55}$ Similarly, in animal models of ischemic stroke, inhibition of PARP using 3-aminobenzamide (3-AB) significantly reduced brain and plasma levels of matrix metalloproteinase 9 (MMP 9), brain nuclear factor KappaB (NF-kB), and neutrophil infiltration as assessed by myeloperoxidase activity. ${ }^{56,57}$ Thus, in addition to its potential for use in cancer therapy, the modulation of the PARP pathway may have important implications for other disease states. Recent studies suggest that PARP knockout mice are highly susceptible to diet-induced obesity. ${ }^{58}$ Compared to their wild-type counterparts, PARP knockout mice display fat accumulation, hyperleptinemia, insulin resistance, and glucose intolerance; this weight gain is due in part to decreased metabolic rate and total energy expenditure. ${ }^{58}$ These findings argue for an important role of the PARP pathway in obesity. 


\section{PARP1 AND TUMOR-SELECTIVE PROGRAMMED NECROSIS (BETA- LAPACHONE)}

There is evidence that the PARP1 hyperactivation pathway itself may also be exploited to selectively kill certain types of cancer cells. Beta-lapachone ( $\beta$-LAP) is a chemotherapeutic and radiosensitizer agent that causes the initiation and execution of apoptosis in cancer cells with characteristic DNA ladder formation. ${ }^{59}$ In HL-60 cells, this apoptosis was also associated with activation of caspase 3 and proteolytic cleavage of PARP, and could be inhibited by expression of the apotosis regulator Bcl2 ${ }^{59}$ Findings in MCF7 cells, however, also showed that $\beta$-LAP, at higher concentrations, killed cells through cell-cycleindependent activation of a noncaspase proteolytic pathway. ${ }^{60}$ Subsequent studies uncovered a novel mechanism of PARP1-mediated cell death in response to agents that generate ROS; in cells with elevated levels of the two-electron reductase NAD $(\mathrm{P}) \mathrm{H}$ :quinone oxidoreductase 1 (NQO1), $\beta$-LAP caused a depletion of NAD+ and ATP that were at least partly mediated by PARP1, since inhibitors of PARP abrogated these effects and the ensuing apoptotic program. ${ }^{61}$ These findings established PARP1-mediated NAD+ and ATP depletion as essential upstream events in the $\beta$-LAP-mediated cell death pathway. ${ }^{61}$ Accordingly, it has also been shown that lung cancer cells expressing high levels of NQO1 are selectively killed by $\beta$-LAP treatment in a manner that involved ROS formation, extensive DNA damage, and PARP1 hyperactivation, and this pathway could be blocked with PARP inhibition. ${ }^{62}$ By comparison, prostate cancer cells (LNCaP) that are deficient in NQO1 were resistant to killing by $\beta$-LAP, and these findings demonstrated that NQO1 activity was a key determinant of $\beta$-LAP toxicity in prostate cancer cells. ${ }^{63}$ MCF7 breast cancer cells expressing NQO1 also undergo a proteolytic apotosis pathway that involves activation of mu-calpain and is independent of caspase activation. ${ }^{64}$

As noted above, PARP1 has been shown to be necessary for initiation of cell death by $\beta$ LAP and calcium has been found to be an important cofactor in this process ${ }^{61}$ From a kinetic standpoint, cell death by $\beta$-LAP has been shown to involve reactive oxygen species (ROS) formation with extensive DNA damage, PARP1 hyperactivation, depletion of NAD +/ATP levels, proteolytic cleavage of p53/PARP1, mu-calpain activation, and apoptosis (Fig. 3). ${ }^{62}$ PARP1 hyperactivation, depletion of nucleotides, and apoptosis could be blocked with a calcium chelator or PARP inhibitor. ${ }^{62} \beta$-LAP has also been shown to act as a potent radiosensitizing agent. $\beta$-LAP sensitized NQO1-expressing prostate cancer cells to ionizing radiation (IR) through a mechanism involving NQO1 bioactivation, induction of ROS, irreversible DNA damage via SSB, and PARP hyperactivation with NAD+/ATP depletion and mu-calpain-induced necrosis. ${ }^{65}$ Furthermore, this radiosensitization by $\beta$-LAP was also blocked with PARP inhibition or the NQO1 inhibitor dicoumarol. ${ }^{65}$ This synergistic combination of radiation with $\beta$-LAP was effective when $\beta$-LAP was administered between 0 and $10 \mathrm{~h}$ following irradiation, which served to upregulate NQO1 levels; $\beta$-LAP in turn sensitized the cells by inhibiting the repair of sublethal radiation damage. ${ }^{66} \beta$-LAP has also been found to synergize with IR in its antitumor effects in mouse xenograft models; these finding suggest that $\beta$-LAP may be an effective radiosensitizer in prostate cancers that overexpress NQO1. ${ }^{65}$ Taken together, these findings demonstrate that the actions of $\beta$-LAP, 
which closely involve the PARP pathway, may be useful to selectively kill cells with NQO1 overexpression, and increase their sensitivity to radiotherapy.

\section{EXPLOITING PARP1 PROCESSES USING THERANOSTIC NANOMEDICINE}

The first endeavor to enhance the solubility and bioavailability of $\beta$-LAP was undertaken using cyclodextrin inclusion complexes (alpha-, beta-, gamma-, and HPbeta-CD) by Gao and coworkers. ${ }^{67}$ Their findings showed that the complexing of $\beta$-LAP with HPbeta-CD improved its solubility and bioavailability, with a TD50 of 2.1 microM observed in cytotoxicity studies. ${ }^{67}$ Nano-delivery vehicles such as polymer micelles have also been used to enhance the solubility and biocompatibility of $\beta$-LAP, and these $\beta$-LAP micelles have been shown to be effective in killing a variety of tumor cells expressing NQO1 with a similar cytotoxic effect involving PARP1 hyperactivation as the free drug. ${ }^{68}$ More recently, these polymer micelles have been shown in mouse xenograft models to exhibit prolonged blood circulation, with a half-life of $\sim 28 \mathrm{~h}$, and increased accumulation in tumors, with an accompanying delay in tumor growth and increased survival. ${ }^{69}$ Finally, $\beta$-LAP-encapsulated polymer implants (millirods) have been demonstrated to achieve tumor-specific therapeutic effects with site-specific release after direct implantation into prostate tumors. ${ }^{70,71}$ Implantation of $\beta$-LAP millirods into prostate tumor xenografts demonstrated significant tumor regression and enhanced survival. These findings offer an attractive potential therapy for prostate tumors expressing NQO1 with minimal systemic toxicity observed. ${ }^{71}$

\section{POTENTIAL UTILITY OF OTHER PARPS IN CANCER (TELOMERIC PARP)}

Telomeres are DNA-protein complexes that protect chromosome ends in eukaryotic cells, and the "end replication" problem refers to the inability of the DNA replication machinery to replicate the very ends of DNA, resulting in a gradual loss of telomeres with each replication of DNA. ${ }^{72-74}$ Although new telomeric DNA can be synthesized by telomerase, the level of telomerase activity is generally insufficient to prevent progressive attrition of telomeres in most somatic cells; this results in replicative senescence. ${ }^{73}$ In contrast, because the majority of cancer cells have high telomerase activity, they can continue to replicate indefinitely and this forms the basis for the use of telomerase inhibitors as cancer therapy. ${ }^{73,74}$ The disadvantage of telomerase inhibition, however, is the need for the continued cell division and consequently the repetition of the end replication problem that ultimately results in senescence and cell death. ${ }^{73,74}$ In addition, the long treatment periods required for sufficient telomere loss to occur can result in the emergence of resistance to telomerase inhibitors. ${ }^{73,74}$ It has been suggested that increasing the efficiency of telomere shortening and therefore hastening the onset of the "crisis" would be a more favorable approach for targeting the cancer cell. ${ }^{73,74}$ In this regard, TRF-1 interacting ankyrin-related ADP-ribose polymerase 1, or tankyrase 1 (also known as PARP 5a), has been shown to enhance access of telomeres to telomerase in a manner dependent on its ADP-ribosylating activity, thereby enhancing telomere elongation by telomerase. ${ }^{73,75}$ As such, increased expression and/or activity of tankyrase 1 can thereby promote telomere elongation in the 
face of telomerase inhibition. Consistent with this notion, tankyrase 1 has been found to be overexpressed in certain cancer cells including gastric cancer and breast cancer.

Significantly higher expression of tankyrase 1 has been detected in human breast tumor tissues as compared to uninvolved normal breast tissue. ${ }^{76}$ Expression of tankyrase 1 was also significantly elevated at both the mRNA and protein level in gastric cancers as compared to normal tissues, and this increased expression was further correlated with increased telomerase activity compared to normal tissue. ${ }^{77}$ Moreover, the inhibition of tankyrase 1 using antisense RNA has been found to enhance the shortening of telomeres in gastric cancer cells without affecting telomerase activity, suggesting that tankyrase 1 may be a valid target for inhibition for this and other cancers. ${ }^{78}$

Because the PARP activity of tankyrase 1 is required for its activity in promoting telomere elongation, the use of PARP inhibitors, in conjunction with telomerase inhibitors, has also been suggested as a means to synergize and enhance the activity of the latter in cancer cells. ${ }^{73}$ Interestingly, recent findings from Ji and coworkers suggest that iniparib (BSI-201) was distinct from three other PARP inhibitors in that it did not show activity as an inhibitor of PARP1 or PARP2 in A375 tumor xenografts, or of PARP1 in BRCA-deficient MX-1 cells, MCF7 cells, or healthy donor peripheral blood mononuclear cells. ${ }^{79}$ However, in this study, iniparib and another PARP inhibitor (ABT-888) caused dose- and time-dependent increases in phosphorylated histone $\mathrm{H} 2 \mathrm{AX}(\gamma-\mathrm{H} 2 \mathrm{AX})$, a marker of DNA damage, independent of PARP inhibition in MX-1 cells, suggesting that these agents both induced DNA damage in a BRCA1-negative background. ${ }^{79}$ Both iniparib and ABT-888 increased telomeric $\gamma-\mathrm{H} 2 \mathrm{AX}$ foci, however, only iniparib increased telomeric $\gamma-\mathrm{H} 2 \mathrm{AX}$ foci, and these findings were consistent with differential gene expression and sequence analyses, which further suggested that iniparib suppressed genes in the telomere maintenance pathway, including DKC1 and PINX1. ${ }^{79}$ These findings have important implications regarding the PARP specificity of these inhibitors and raise the interesting prospect that iniparib, unlike other PARP inhibitors, may act specifically on telomeric PARP.

As noted earlier, PARP1 is the first and best characterized member of the PARP family, and has been the focus of most of the studies described herein. Many other members of the PARP family, however, have been characterized and their requirement for PARP enzymatic activity could further expand the therapeutic potential of PARP inhibitors. ${ }^{1}$ PARP3, a newly characterized member of the PARP family, also appears to function in the cellular response to DSBs, and is important in the stabilization of the mitotic spindle and telomere integrity. ${ }^{80}$ Interestingly, PARP3 has also been shown to interact with and regulate tankyrase 1, and these functions may be potentially important for cancer therapeutics. Vault PARP (VPARP, PARP4) is a component of the large ribonucleoprotein complex, the vault particle, and, although initial gene targeting experiments failed to identify a function, subsequent work has shown that VPARP-deficient mice are more susceptible to carcinogen-induced tumorigenesis. ${ }^{1,81,82}$ A second tankyrase, tankyrase 2 (PARP5b) has also been identified that has some distinct properties from tankyrase 1, however, gene targeting experiments suggest that this tankyrase is functionally redundant with tankyrase 1 during mouse development. ${ }^{83,84}$ Further study will be necessary to elucidate the molecular basis and implications of this redundancy, as well as the redundancy of other PARP homologs (e.g., PARP1 and PARP2). ${ }^{1}$ As additional PARPs are identified, and the functions of the various 
PARP family members are elucidated, their potential utility as therapeutic targets in cancer and other disease processes is likely to expand even further.

\section{SUMMARY AND CONCLUSIONS}

PARP is a critical enzyme involved in DNA repair and many other cellular processes including transcription and modulation of chromatin structure. PARP plays a central role in NER and BER, and enables repair of DNA damage caused by alkylating agents and chemotherapeutic drugs. Studies have demonstrated that PARP is upregulated in certain cancers including TNBC and those that express BRCA1 mutations. Because certain tumor types (e.g. BRCA1 mutants) are more dependent on PARP, they are also more sensitive to "synthetic lethality" with PARP inhibitors. PARP inhibition may also be useful in combination with chemotherapy to selectively sensitize cancer cells to DNA damaging agents and promote tumor cell death.

Other mechanisms by which PARP exerts its effects are via rapid mitochondrial dysfunction with membrane permeability transition, NAD+ depletion, and translocation of AIF from the mitochondria to the nucleus. Inhibition/manipulation of other components of the PARP pathway, including PAR and PARG, may be therefore be useful therapeutic interventions not only for cancer, but for other disease states. Hyperactivation of PARP1 may also be exploited to selectively kill cancer cells with agents such as $\beta$-LAP, and the combination of this drug with novel delivery systems may offer promising new therapeutic options for patients. Finally, other PARP family members such as telomeric PARPs (tankyrases) may offer another potential avenue for therapeutic intervention in cancer and possibly other disease states. The specificity of the different PARP inhibitors that are currently under development and/or undergoing clinical evaluation could further expand the utility of PARP and its inhibition.

\section{References}

1. Amé J-C, Spenlehauer C, de Murcia G. The PARP super-family. BioEssays. 2004; 26(8):882-93. [PubMed: 15273990]

2. D’Amours D, Desnoyers S, D'Silva I, Poirier GG. Poly(ADP-ribosyl)ation reactions in the regulation of nuclear functions. Biochem J. 1999; 342(2):249-68. [PubMed: 10455009]

3. Amé JC, Rolli V, Schreiber V, Niedergang C, Apiou F, Decker P, Muller S, Höger T, Ménissier-de Murcia J, de Murcia G. PARP-2, A Novel Mammalian DNA Damage-dependent Poly(ADP-ribose) Polymerase. J Biol Chem. 1999; 274(25):17860-8. [PubMed: 10364231]

4. Skidmore CJ, Davies MI, Goodwin PM, Halldorsson H, Lewis PJ, Shall S, Zia'ee AA. The involvement of poly(ADP-ribose) polymerase in the degradation of NAD caused by gammaradiation and N-methyl-N-nitrosourea. Eur J Biochem. 1979; 101(1):135-42. [PubMed: 228934]

5. Juarez-Salinas H, Sims JL, Jacobson MK. Poly(ADP-ribose) levels in carcinogen-treated cells. Nature. 1979; 282(5740):740-1. [PubMed: 229416]

6. Caldecott KW, Aoufouchi S, Johnson P, Shall S. XRCC1 polypeptide interacts with DNA polymerase $\beta$ and possibly poly (ADP-ribose) polymerase, and DNA ligase III is a novel molecular 'nick-sensor' in vitro. Nucleic Acids Res. 1996; 24(22):4387-94. [PubMed: 8948628]

7. Satoh MS, Lindahl T. Role of poly(ADP-ribose) formation in DNA repair. Nature. 1992; 356(6367): 356-8. [PubMed: 1549180]

8. Dantzer F, Giraud-Panis MJ, Jaco I, Amé JC, Schultz I, Blasco M, Koering CE, Gilson E, Ménissier-de Murcia J, de Murcia G, Schreiber V. Functional interaction between poly(ADP-ribose) 
polymerase 2 (PARP-2) and TRF2: PARP activity negatively regulates TRF2. Mol Cell Biol. 2004; 24(4):1595-607. [PubMed: 14749375]

9. Schreiber V, Amé JC, Dollé P, Schultz I, Rinaldi B, Fraulob V, Ménissier-de Murcia J, de Murcia G. Poly(ADP-ribose) polymerase-2 (PARP-2) is required for efficient base excision DNA repair in association with PARP-1 and XRCC1. J Biol Chem. 2002; 277(25):23028-36. [PubMed: 11948190]

10. Flohr C, Bürkle A, Radicella JP, Epe B. Poly(ADP, Äêribosyl)ation accelerates DNA repair in a pathway dependent on Cockayne syndrome B protein. Nucleic Acids Res. 2003; 31(18):5332-7. [PubMed: 12954769]

11. Helleday T, Petermann E, Lundin C, Hodgson B, Sharma RA. DNA repair pathways as targets for cancer therapy. Nat Rev Cancer. 2008; 8(3):193-204. [PubMed: 18256616]

12. de Murcia JM, Niedergang C, Trucco C, Ricoul M, Dutrillaux B, Mark M, Oliver FJ, Masson M, Dierich A, LeMeur M, Walztinger C, Chambon P, de Murcia G. Requirement of poly(ADP-ribose) polymerase in recovery from DNA damage in mice and in cells. Proc Natl Acad Sci U S A. 1997; 94(14):7303-7. [PubMed: 9207086]

13. Parker RJ, Eastman A, Bostick-Bruton F, Reed E. Acquired cisplatin resistance in human ovarian cancer cells is associated with enhanced repair of cisplatin-DNA lesions and reduced drug accumulation. J Clin Invest. 1991; 87(3):772-7. [PubMed: 1999494]

14. Yu SW, Andrabi SA, Wang H, Kim NS, Poirier GG, Dawson TM, Dawson VL. Apoptosisinducing factor mediates poly(ADP-ribose) (PAR) polymer-induced cell death. Proc Natl Acad Sci U S A. 2006; 103(48):18314-9. [PubMed: 17116881]

15. Jacobson EL, Smith JY, Wielckens K, Hilz H, Jacobson MK. Cellular recovery of dividing and confluent C3H10T1/2 cells from N-methyl- $\mathrm{N}^{\prime}$-nitro-N-nitrosoguanidine in the presence of ADP ribosylation inhibitors. Carcinogenesis. 1985; 6(5):715-8. [PubMed: 2988808]

16. Schreiber V, Hunting D, Trucco C, Gowans B, Grunwald D, De Murcia G, De Murcia JM. A dominant-negative mutant of human poly(ADP-ribose) polymerase affects cell recovery, apoptosis, and sister chromatid exchange following DNA damage. Proc Natl Acad Sci U S A. 1995; 92(11):4753-7. [PubMed: 7761396]

17. Molinete M, Vermeulen W, Bürkle A, Ménissier-de Murcia J, Küpper JH, Hoeijmakers JH, de Murcia G. Overproduction of the poly(ADP-ribose) polymerase DNA-binding domain blacks alkylation-induced DNA repair synthesis in mammalian cells. EMBO. 1993; 5(12):2109-17.

18. Nomura F, Yaguchi M, Togawa A, Miyazaki M, Isobe K, Miyake M, Noda M, Nakai T. Enhancement of poly-adenosine diphosphate-ribosylation in human hepatocellular carcinoma. $\mathrm{J}$ Gastroenterol Hepatol. 2000; 15(5):529-35. [PubMed: 10847440]

19. Ossovskaya V, Koo IC, Kaldjian EP, Alvares C, Sherman BM. Upregualtion of poly (ADP-ribose) polymerase-1 (Parp1) in Triple-Negative Breast Cancer And Other Primary Human Tumor Types. Genes Cancer. 2010; 8:812-21. [PubMed: 21779467]

20. Moynahan ME, Chiu JW, Koller BH, Jasin M. Brca1 Controls Homology-Directed DNA Repair. Molecular cell. 1999; 4(4):511-8. [PubMed: 10549283]

21. Donoho G1, Brenneman MA, Cui TX, Donoviel D, Vogel H, Goodwin EH, Chen DJ, Hasty P. Deletion of Brca2 exon 27 causes hypersensitivity to DNA crosslinks, chromosomal instability, and reduced life span in mice. Genes Chromosomes Cancer. 2003; 36(4):317-31. [PubMed: 12619154]

22. McCabe N, Turner NC, Lord CJ, Kluzek K, Bialkowska A, Swift S, Giavara S, O'Connor MJ, Tutt AN, Zdzienicka MZ, Smith GC, Ashworth A. Deficiency in the repair of DNA damage by homologous recombination and sensitivity to poly(ADP-ribose) polymerase inhibition. Cancer Res. 2006; 66(16):8109-15. [PubMed: 16912188]

23. Kyle S, Thomas HD, Mitchell J, Curtin NJ. Exploiting the Achilles heel of cancer: the therapeutic potential of poly(ADP-ribose) polymerase inhibitors in BRCA2-defective cancer. Br J Radiol. 2008; 81(Special Issue_1):S6-11. [PubMed: 18820000]

24. Farmer H, McCabe N, Lord CJ, Tutt AN, Johnson DA, Richardson TB, Santarosa M, Dillon KJ, Hickson I, Knights C, Martin NM, Jackson SP, Smith GC, Ashworth A. Targeting the DNA repair defect in BRCA mutant cells as a therapeutic strategy. Nature. 2005; 434(7035):917-21. [PubMed: 15829967] 
25. Bryant HE, Schultz N, Thomas HD, Parker KM, Flower D, Lopez E, Kyle S, Meuth M, Curtin NJ, Helleday T. Specific killing of BRCA2-deficient tumours with inhibitors of poly(ADP-ribose) polymerase. Nature. 2005; 434(7035):913-7. [PubMed: 15829966]

26. Domagala P, Huzarski T, Lubinski J, Gugala K, Domagala W. Immunophenotypic predictive profiling of BRCA1-associated breast cancer. Virchows Archiv. 2011; 458(1):55-64. [PubMed: 20941507]

27. Bouwman P, Aly A, Escandell JM, Pieterse M, Bartkova J, van der Gulden H, Hiddingh S, Thanasoula M, Kulkarni A, Yang Q, Haffty BG, Tommiska J, Blomqvist C, Drapkin R, Adams DJ, Nevanlinna H, Bartek J, Tarsounas M, Ganesan S, Jonkers J. 53BP1 loss rescues BRCA1 deficiency and is associated with triple-negative and BRCA-mutated breast cancers. Nat Struct Mol Biol. 17(6):688-95. [PubMed: 20453858]

28. Bunting SF, Callén E, Wong N, Chen HT, Polato F, Gunn A, Bothmer A, Feldhahn N, FernandezCapetillo O, Cao L, Xu X, Deng CX, Finkel T, Nussenzweig M, Stark JM, Nussenzweig A. 53BP1 inhibits homologous recombination in brca1-deficient cells by blocking resection of DNA breaks. Cell. 141(2):243-54. [PubMed: 20362325]

29. Mukhopadhyay A, Elattar A, Cerbinskaite A, Wilkinson SJ, Drew Y, Kyle S, Los G, Hostomsky Z, Edmondson RJ, Curtin NJ. Development of a functional assay for homologous recombination status in primary cultures of epithelial ovarian tumor and correlation with sensitivity to poly(ADPribose) polymerase inhibitors. Clin Cancer Res. 16(8):2344-51. [PubMed: 20371688]

30. Poirier GG, de Murcia G, Jongstra-Bilen J, Niedergang C, Mandel P. Poly(ADP-ribosyl)ation of polynucleosomes causes relaxation of chromatin structure. Proc Nat Acad Sci U S A. 1982; 79(11):3423-7.

31. Gottschalk AJ, Timinszky G, Kong SE, Jin J, Cai Y, Swanson SK, Washburn MP, Florens L, Ladurner AG, Conaway JW, Conaway RC. Poly(ADP-ribosyl)ation directs recruitment and activation of an ATP-dependent chromatin remodeler. Proc Natl Acad Sci U S A. 2009; 106(33): 13770-4. [PubMed: 19666485]

32. Mullins D, Giri C, Smulson M. Poly(adenosine disphosphate-ribose) polymerase: the distribution of a chromosome-associated enzyme within the chromatin substructure. Biochemistry. 1977; 16(3):506-13. [PubMed: 189803]

33. Meisterernst M, Stelzer G, Roeder RG. Poly(ADP-ribose) polymerase enhances activatordependent transcription in vitro. Proc Natl Acad Sci. 1997; 94(6):2261-5. [PubMed: 9122182]

34. Butler AJ, Ordahl CP. Poly(ADP-ribose) polymerase binds with transcription enhancer factor 1 to MCAT1 elements to regulate muscle-specific transcription. Mol Cell Biol. 1999; 19(1):296-306. [PubMed: 9858553]

35. Kannan P, Yu Y, Wankhade S, Tainsky MA. PolyADP-ribose polymerase is a coactivator for AP-2-mediated transcriptional activation. Nucleic Acids Res. 1999; 27(3):866-74. [PubMed: 9889285]

36. Miyamoto T, Kakizawa T, Hashizume K. Inhibition of nuclear receptor signalling by poly(ADPribose) polymerase. Mol Cell Biol. 1999; 19(4):2644-9. [PubMed: 10082530]

37. Krishnakumar R, Kraus WL. PARP-1 regulates chromatin structure and transcription through a KDM5B-dependent pathway. Mol Cell. 39(5):736-49. [PubMed: 20832725]

38. Berger NA, Berger SJ, Catino DM, Petzold SJ, Robins RK. Modulation of nicotinamide adenine dinucleotide and poly(adenosine diphosphoribose) metabolism by the synthetic " $\mathrm{C}$ " nucleoside analogs, tiazofurin and selenazofurin. a new strategy for cancer chemotherapy. J Clin Invest. 1985; 75(2):702-9. [PubMed: 3919063]

39. Chiarugi A. Inhibitors of poly(ADP-ribose) polymerase-1 suppress transcriptional activation in lymphocytes and ameliorate autoimmune encephalomyelitis in rats. Br J Pharmacol. 2002; 137(6): 761-70. [PubMed: 12411406]

40. Alano CC, Ying W, Swanson RA. Poly(ADP-ribose) polymerase-1-mediated cell death in astrocytes requires NAD+ depletion and mitochondrial permeability transition. J Biol Chem. 2004; 279(18):18895-902. [PubMed: 14960594]

41. Cipriani G, Rapizzi E, Vannacci A, Rizzuto R, Moroni F, Chiarugi A. Nuclear poly(ADP-ribose) polymerase-1 rapidly triggers mitochondrial dysfunction. J Biol Chem. 2005; 280(17):17227-34. [PubMed: 15750180] 
42. Formentini L, Macchiarulo A, Cipriani G, Camaioni E, Rapizzi E, Pellicciari R, Moroni F, Chiarugi A. Poly(ADP-ribose) catabolism triggers AMP-dependent mitochondrial energy failure. J Biol Chem. 2009; 284(26):17668-76. [PubMed: 19411252]

43. Yu SW, Wang H, Poitras MF, Coombs C, Bowers WJ, Federoff HJ, Poirier GG, Dawson TM, Dawson VL. Mediation of poly(ADP-ribose) polymerase-1-dependent cell death by apoptosisinducing factor. Science. 2002; 297(5579):259-63. [PubMed: 12114629]

44. Wang Y, Kim NS, Li X, Greer PA, Koehler RC, Dawson VL, Dawson TM. Calpain activation is not required for AIF translocation in PARP-1-dependent cell death (parthanatos). J Neurochem. 2009; 110(2):687-96. [PubMed: 19457082]

45. Kang YH, Yi MJ, Kim MJ, Park MT, Bae S, Kang CM, Cho CK, Park IC, Park MJ, Rhee CH, Hong SI, Chung HY, Lee YS, Lee SJ. Caspase-independent cell death by arsenic trioxide in human cervical cancer cells. Cancer Res. 2004; 64(24):8960-7. [PubMed: 15604259]

46. Moubarak RS, Yuste VJ, Artus C, Bouharrour A, Greer PA, Menissier-de Murcia J, Susin SA. Sequential activation of poly(ADP-ribose) polymerase 1, calpains, and bax is essential in apoptosis-inducing factor-mediated programmed necrosis. Mol Cell Biol. 2007; 27(13):4844-62. [PubMed: 17470554]

47. Siegel C, McCullough LD. NAD+ depletion or PAR polymer formation: which plays the role of executioner in ischaemic cell death? Acta Physiol. 203(1):225-34.

48. Heeres JT, Hergenrother PJ. Poly(ADP-ribose) makes a date with death. Curr Opin Chemical Biol. 2007; 11(6):644-53.

49. Andrabi SA, Kim NS, Yu SW, Wang H, Koh DW, Sasaki M, Klaus JA, Otsuka T, Zhang Z, Koehler RC, Hurn PD, Poirier GG, Dawson VL, Dawson TM. Poly(ADP-ribose) (PAR) polymer is a death signal. Proc Natl Acad Sci U S A. 2006; 103(48):18308-13. [PubMed: 17116882]

50. Ame JC, Hakme A, Quenet D, Fouquerel E, Dantzer F, Shchreiber V. Detection of the nuclear poly(ADP-ribose)-metabolizing and activities in response to DNA damage. Methods Mol Biol. 2009; 464:267-83. [PubMed: 18951190]

51. Koh DW, Dawson VL, Dawson TM. The road to survival goes through PARG. Cell Cycle. 2005; 4(3):397-9. [PubMed: 15725727]

52. Amé JC, Fouquerel E, Gauthier LR, Biard D, Boussin FD, Dantzer F, de Murcia G, Schreiber V. Radiation-induced mitotic catastrophe in PARG-deficient cells. J Cell Sci. 2009; 122(12):19902002. [PubMed: 19454480]

53. Min W, Wang Z. Poly (ADP-ribose) glycohydrolase (PARG) and its therapeutic potential. Front Biosci. 2009; 14:1619-26.

54. Fauzee N, Pan J, Wang Y-1. PARP and PARG inhibitors-new therapeutic targets in cancer treatment. Pathol Oncol Res. 16(4):469-78. [PubMed: 20383759]

55. Lenzsér G, Kis B, Snipes JA, Gáspár T, Sándor P, Komjáti K, Szabó C, Busija DW. Contribution of poly(ADP-ribose) polymerase to postischemic blood-brain barrier damage in rats. J Cereb Blood Flow Metab. 2007; 27(7):1318-26. [PubMed: 17213862]

56. Koh SH, Roh H, Lee SM, Kim HJ, Kim M, Lee KW, Kim HT, Kim J, Kim SH. Phosphatidylinositol 3-kinase activator reduces motor neuronal cell death induced by G93A or A4V mutant SOD1 gene. Toxicology. 2005; 213(1-2):45-55. [PubMed: 15996807]

57. Moroni F, Chiarugi A. Post-ischemic brain damage: targeting PARP-1 within the ischemic neurovascular units as a realistic avenue to stroke treatment. FEBS J. 2009; 276(1):36-45. [PubMed: 19087198]

58. Devalaraja-Narashimha K, Padanilam BJ. PARP1 deficiency exacerbates diet-induced obesity in mice. J Endocrinology. 205(3):243-52. [PubMed: 20338998]

59. Planchon SM, Wuerzberger-Davis SM, Pink JJ, Robertson KA, Bornmann WG, Boothman DA. Bcl-2 protects against beta-lapachone-mediated caspase 3 activation and apoptosis in human myeloid leukemia (HL-60) cells. Oncol Rep. 1999; 6(3):485-92. [PubMed: 10203579]

60. Pink JJ, Wuerzberger-Davis S, Tagliarino C, Planchon SM, Yang X, Froelich CJ, Boothman DA. Activation of a Cysteine Protease in MCF-7 and T47D Breast Cancer Cells during OE $\leq$ Lapachone-Mediated Apoptosis. Exp Cell Res. 2000; 255(2):144-55. [PubMed: 10694431] 
61. Bentle MS, Reinicke KE, Bey EA, Spitz DR, Boothman DA. Calcium-dependent modulation of poly(ADP-ribose) polymerase-1 alters cellular metabolism and DNA repair. J Biol Chem. 2006; 281(44):33684-96. [PubMed: 16920718]

62. Bey EA, Bentle MS, Reinicke KE, Dong Y, Yang CR, Girard L, Minna JD, Bornmann WG, Gao J, Boothman DA. An NQO1- and PARP-1-mediated cell death pathway induced in non-small-cell lung cancer cells by beta-lapachone. Proc Natl Acad Sci USA. 2007; 104(28):11832-7. [PubMed: 17609380]

63. Planchon SM, Pink JJ, Tagliarino C, Bornmann WG, Varnes ME, Boothman DA. Beta-lapachoneinduced apoptosis in human prostate cancer cells: involvement of NQO1/xip3. Exp Cell Res. 2001; 267(1):95-106. [PubMed: 11412042]

64. Tagliarino C, Pink JJ, Reinicke K, Simmers SM, Boothman DA. Mu-Calpain activation in betalapachone-mediated apoptosis. Cancer Biol Therapy. 2003; 2(2):140-50.

65. Dong Y, Bey EA, Li LS, Kabbani W, Yan J, Xie XJ, Hsieh JT, Gao J, Boothman DA. Prostate cancer radiosensitization through poly(ADP-ribose) polymerase-1 hyperactivation. Cancer Res. 2010; 70(20):8088-96. [PubMed: 20940411]

66. Suzuki M, Amano M, Choi J, Park HJ, Williams BW, Ono K, Song CW. Synergistic effects of radiation and beta-lapachone in DU-145 human prostate cancer cells in vitro. Radiat Res. 2006; 165(5):525-31. [PubMed: 16669706]

67. Nasongkla N, Wiedmann AF, Bruening A, Beman M, Ray D, Bornmann WG, Boothman DA, Gao J. Enhancement of solubility and bioavailability of $\beta$-lapachone using cyclodextrin inclusion complexes. Pharm Res. 2003; 20(10):1626-33. [PubMed: 14620518]

68. Blanco E, Bey EA, Dong Y, Weinberg BD, Sutton DM, Boothman DA, Gao J. Beta-lapachonecontaining PEG-PLA polymer micelles as novel nanotherapeutics against NQO1-overexpressing tumor cells. J Controlled Release. 2007; 122(3):365-74.

69. Blanco E, Bey EA, Khemtong C, Yang SG, Setti-Guthi J, Chen H, Kessinger CW, Carnevale KA, Bornmann WG, Boothman DA, Gao J. Beta-lapachone micellar nanotherapeutics for non-small cell lung cancer therapy. Cancer Res. 2010; 70(10):3896-904. [PubMed: 20460521]

70. Wang F, Saidel GM, Gao J. A mechanistic model of controlled drug release from polymer millirods: effects of excipients and complex binding. J Controlled Release. 2007; 119(1):111-20.

71. Dong Y, Chin SF, Blanco E, Bey EA, Kabbani W, Xie XJ, Bornmann WG, Boothman DA, Gao J. Intratumoral delivery of beta-lapachone via polymer implants for prostate cancer therapy. ClinCancer Res. 2009; 15(1):131-9.

72. Blackburn EH. Switching and signaling at the telomere. Cell. 2001; 106(6):661-73. [PubMed: 11572773]

73. Seimiya H. The telomeric PARP, tankyrases, as targets for cancer therapy. Br J Cancer. 2006; 94(3):341-5. [PubMed: 16421589]

74. Seimiya H, Muramatsu Y, Ohishi T, Tsuruo T. Tankyrase 1 as a target for telomere-directed molecular cancer therapeutics. Cancer Cell. 2005; 7(1):25-37. [PubMed: 15652747]

75. Smith S, de Lange T. Tankyrase promotes telomere elongation in human cells. Curr Biol. 2000; 10(20):1299-302. [PubMed: 11069113]

76. Gelmini S, Poggesi M, Distante V, Bianchi S, Simi L, Luconi M, Raggi CC, Cataliotti L, Pazzagli M, Orlando C. Tankyrase, a positive regulator of telomere elongation, is over expressed in human breast cancer. Cancer Lett. 2004; 216(1):81-7. [PubMed: 15500951]

77. Gao J, Zhang J, Long Y, Tian Y, Lu X. Expression of tankyrase 1 in gastric cancer and its correlation with telomerase activity. Pathol Oncol Res. 17(3):685-90. [PubMed: 21455637]

78. Zhang H, Yang MH, Zhao JJ, Chen L, Yu ST, Tang XD, Fang DC, Yang SM. Inhibition of tankyrase 1 in human gastric cancer cells enhances telomere shortening by telomerase inhibitors. Oncol Rep. 2010; 24(4):1059-65. [PubMed: 20811689]

79. Kummar S, Chen A, Parchment R, Kinders R, Ji J, Tomaszewski J, Doroshow JH. Advances in using PARP inhibitors to treat cancer. BMC Med. 2012; 10(1):10-25. [PubMed: 22296610]

80. Boehler C, Gauthier LR, Mortusewicz O, Biard DS, Saliou J-M, Bresson A, Sanglier-Cianferani S, Smith S, Schreiber V, Boussin F, Dantzer F. Poly(ADP-ribose) polymerase 3 (PARP3), a newcomer in cellular response to DNA damage and mitotic progression. Proc Natl Acad Sci U S A. 108(7):2783-8. [PubMed: 21270334] 
81. Liu Y, Snow BE, Kickhoefer VA, Erdmann N, Zhou W, Wakeham A, Gomez M, Rome LH, Harrington L. Vault poly(ADP-ribose) polymerase is associated with mammalian telomerase and is dispensable for telomerase function and vault structure in vivo. Mol Cell Biol. 2004; 24(12): 5314-23. [PubMed: 15169895]

82. Raval-Fernandes S, Kickhoefer VA, Kitchen C, Rome LH. Increased susceptibility of vault poly(ADP-ribose) polymerase-deficient mice to carcinogen-induced tumorigenesis. Cancer Research. 2005; 65(19):8846-52. [PubMed: 16204055]

83. Kaminker PG, Kim SH, Taylor RD, Zebarjadian Y, Funk WD, Morin GB, Yaswen P, Campisi J. TANK2, a New TRF1-associated Poly(ADP-ribose) polymerase, causes rapid induction of cell death upon overexpression. J Biol Chem. 2001; 276(38):35891-9. [PubMed: 11454873]

84. Chiang YJ, Hsiao SJ, Yver D, Cushman SW, Tessarollo L, Smith S, Hodes RJ. Tankyrase 1 and Tankyrase 2 are essential but redundant for mouse embryonic development. PLoS ONE. 2008; 3(7):e2639. [PubMed: 18612384] 


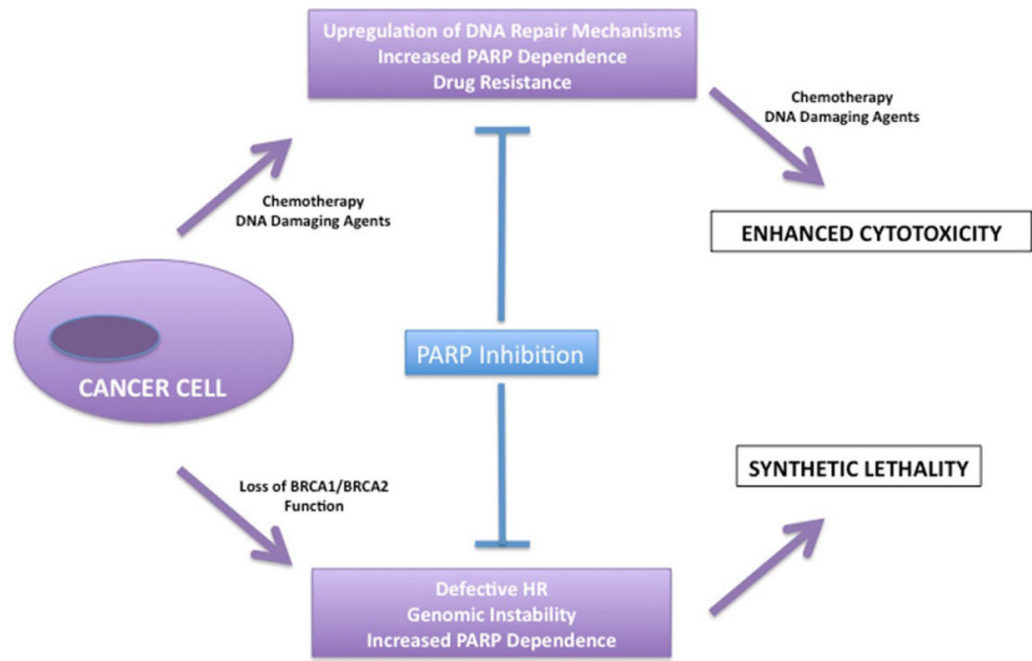

FIG. 1.

Dual therapeutic potential for PARP inhibition in oncology 


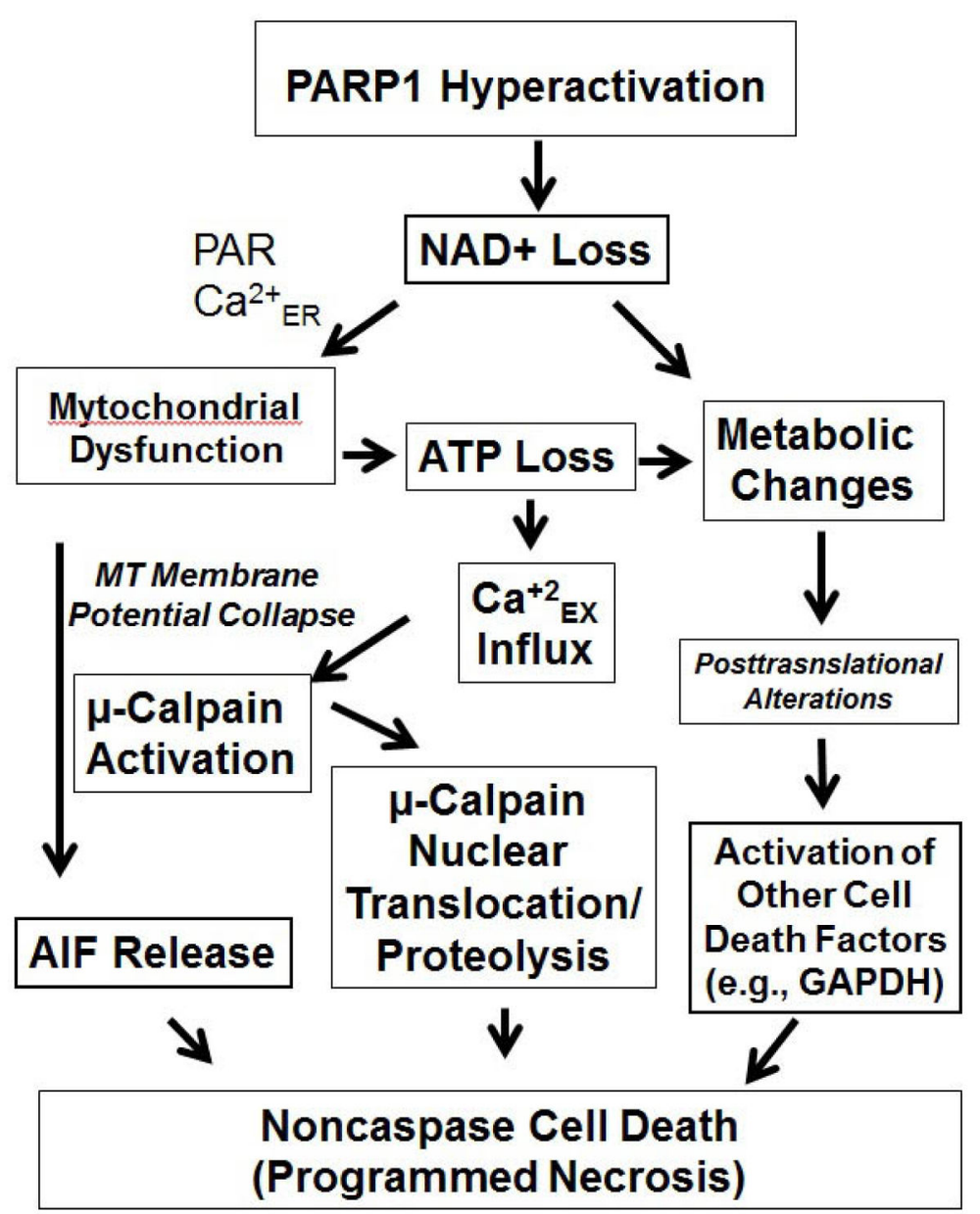

FIG. 2.

PARP-mediated cell death mechanisms 


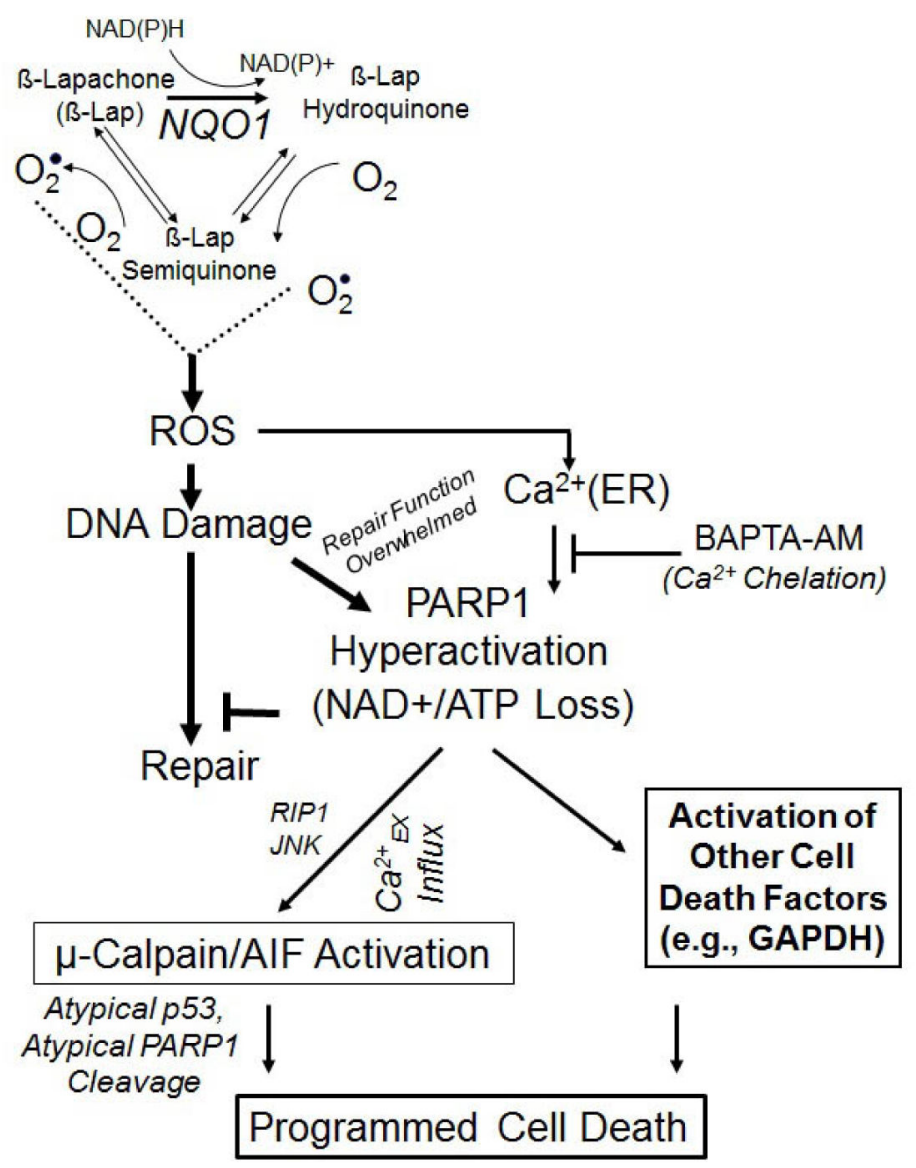

FIG. 3.

Mechanisms of $\beta$-lapachone-induced toxicity in cancer cells 